\title{
Carcinoma papilar hallado en injerto renal tras 13 años de correcto funcionamiento
}

\author{
Serrano Frago P, Gil Martínez P, Plaza Mas L, Allué López M, Gil Sanz Mª J, Rioja Sanz LA. \\ Servicio de Urología. Hospital Universitario Miguel Servet. Zaragoza.
}

Actas Urol Esp. 2006;30(8):829-831

\section{RESUMEN \\ CARCINOMA PAPILAR HALLADO EN INJERTO RENAL TRAS 13 AÑOS DE CORRECTO FUNCIONAMIENTO}

Es conocida la mayor probabilidad de aparición de lesiones malignas en pacientes con trasplante renal debido a su inmunosupresión. Exponemos un caso en el que tras trece años de correcto funcionamiento del trasplante renal se diagnostica de forma casual mediante ecografía de control un tumor sobre el injerto. Mediante punción ecodirigida se evidenció que se trataba de un carcinoma papilar y se realizó trasplantectomía posterior. Planteamos una reflexión acerca de los tumores de novo sobre injerto renal dado el alto número de pacientes con trasplante funcionante durante largos años y la escasa evidencia en la literatura, proponiendo un posible registro de los mismos para valorar su comportamiento y compararlo con los conocidos sobre riñones nativos sin situación de inmunosupresión.

Palabras clave: Carcinoma. Injerto renal.

\section{ABSTRACT \\ CARCINOMA PAPILAR AFTER 13 YEARS OF CORRECT FUNCTION OF GRAFT RENAL}

It is known the greater probability appearance of malignancy injuries in patients with renal graft due to its inmunosupresion. We expose a case in which after thirteen years of correct operation of the renal transplant a tumor is diagnosed of accidental form by means of ultrasonography of graft's control. It was demonstrated by percutaneous biopsy that it was a carcinoma to papilar and later transplanctectomy was made. We raised a reflection about the novo tumors on renal graft given to the high number of patients with funcionante transplant during long years and the little evidence in Literature, proposing a possible registry of such valuing its behavior and comparing it with the well-known ones on native kidneys without inmunosupresión situation.

Keywords: Carcinoma. Renal transplant.

$\mathrm{L}$ a inmunosupresión adquirida en los pacientes trasplantados renales eleva las posibilidades de aparición de lesiones tumorales. Se plantea en la literatura realización de seguimientos, no estando consensuadas las características como son la duración, métodos diagnósticos empleados y tratamiento del mismo. Tampoco aparece una clasificación de las lesiones malignas de novo en injertos renales y comportamiento en estos pacientes.

\section{CASO CLINICO}

Mujer de 41 años controlada en el Servicio de Nefrología desde 1990 por una insuficiencia renal crónica de etiología no filiada que requirió hemodiálisis periódica. A los dos años se realizó trasplante renal heterotópico con injerto de cadáver sobre fosa ilíaca derecha con correcta evolución postoperatoria y manteniéndose unos niveles séricos de creatinina de $1,2 \mathrm{mg} / \mathrm{dl}$. 
Fue remitida a nuestro servicio tras encontrar en una ecografía de control a los trece años del trasplante, dos masas en parénquima de injerto renal sólidas por lo que se realizó una tomografía computadorizada.

En la tomografia computadorizada (TC) se evidenciaron dos masas en tercio superior y medio de contenido sólido compatibles con proceso linfomatoso (Fig. 1) sin imágenes radiológicas de extensión a otros niveles. Ante este hallazgo se realizó punción ecodirigida de las masas renales y la técnicas histo-patológicas diagnosticaron carcinoma renal papilar. Se llevó a cabo la trasplantectomía sin ninguna incidencia intraoperatoria con el diagnóstico final de carcinoma de células renales de tipo papilar que no desbordaba cápsula, p T1 NO M0, según la clasificación internacional de TNM del 2002. Comenzó de nuevo sesiones de hemodiálisis, tras 4 meses del diagnóstico mediante ecografía y TC no se han evidenciado signos de extensión tumoral.

\section{DISCUSIÓN}

El carcinoma renal papilar es el segundo tipo histológico más frecuente de los cánceres renales, representando un 10-15\% de todos, siendo más frecuente en pacientes con fallo renal terminal y con un grado de malignidad bajo y cierta tendencia a la multicentricidad $(40 \%)^{1,2}$.

No se han evidenciado en el presente claras diferencias en cuanto a los resultados comparando el carcinoma renal convencional y el papilar.

Cuando se nos presentó un caso de novo de esta variedad de carcinoma renal epitelio idee sobre un injerto renal realizamos una revisión de la literatura comprobando la escasez de número de casos publicados; en la mayoría se trataban de otras variedades de carcinoma renal y sobre riñones nativos. Al haber pocos casos, no existen claras evidencias acerca del comportamiento de los mismos y su diagnóstico. Se plantean características radiológicas específicas

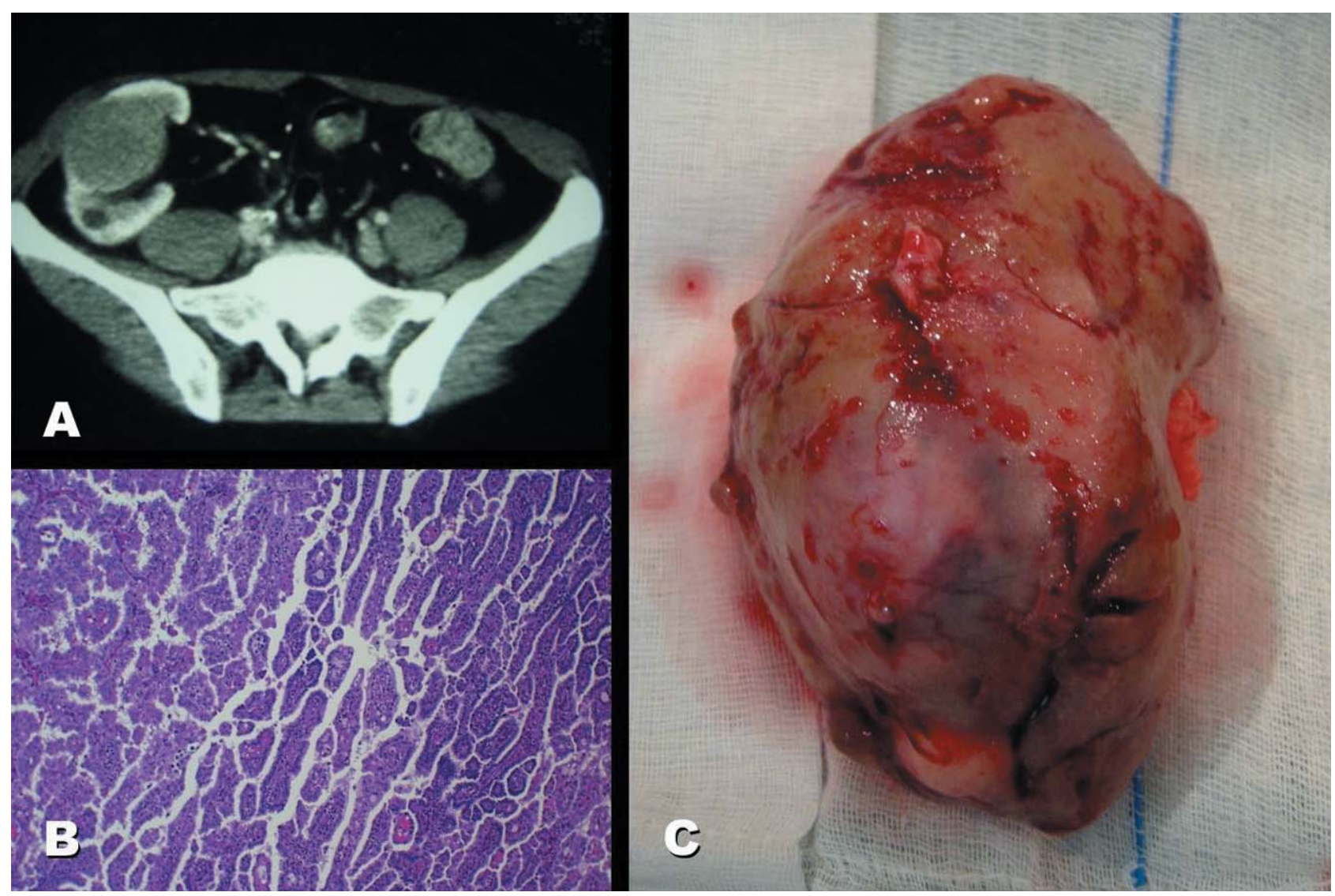

FIGURA 1. (A) TC de abdomen que muestra dos masas sólidas en tercio superior y medio de injerto renal de aspecto sólido. (B) Tinción de hematoxilina eosina que muestra células renales de tipo papilar. (C) Pieza de trasplantectomía. 
de los mismos $^{3}$ mediante resonancia nuclear magnética y el carácter de la multicentricidad posiblemente causada por predisposición genética y el estado de inmunosupresión ${ }^{4}$.

Se han planteado en diferentes artículos la necesidad de controles clínicos y radiológicos de forma periódica incluidos los riñones nativos para diagnóstico precoz dada la frecuencia mayor de carcinoma de células renales en pacientes trasplantados 5 .

Planteamos una reflexión acerca de los tumores de novo sobre injerto renal dado el alto número de pacientes con trasplante funcionante durante largos años y la escasa evidencia en la literatura, proponiendo un posible registro de los mismos para valorar su comportamiento y compararlo con los conocidos sobre riñones nativos sin situación de inmunosupresión.

\section{REFERENCIAS}

1. Storkel S, Eble JN, Adlakha K, Amin M, Blute ML, Bostwick DG, et al. Classification of renal cell carcinoma: Workgroup No.1 Union Internationale Contre le Cancer (UICC) and the American Joint Committee on Cancer (AJCC). Cancer. 1997;80(5):987-989.

2. Doublet JD, Peraldi MN, Gattegno B, Thibault P, Sraer JD. Renal cell carcinoma of native kidneys: prospective study of 129 renal transplant patients. J Urol. 1997 Jul;158(1):42-44.

3. Roy C, El Ghali S, Buy X, Lindner V, Gangi A. Papillary renal cell carcinoma in allograft kidney.Eur Radiol. 2005 Apr; 15(4):661-665.

4. DeLong MJ, Schmitt D, Scott KM, Ramakumar S, Lien YH. Multicentric papillary renal carcinoma in renal allograft. Am J Kidney Dis. 2003 Aug;42(2):381-384.

5. Roupret M, Peraldi MN, Thaunat O, Chretien Y, Thiounn N, Dufour B, et al. Renal cell carcinoma of the grafted kidney: how to improve screening and graft tracking. Transplantation. 2004 Jan; 15;77(1): 146-148.

Dra. P. Serrano Frago

(Trabajo recibido el 31 de agosto 2005) 